Available online at www.jmle.org

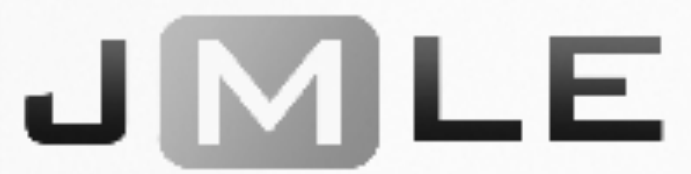

The National Association for Media Literacy Education's

Journal of Media Literacy Education 9 (2), 1 - 16

\title{
Beyond Accessibility: How Media Literacy Education Addresses Issues of Disabilities
}

\author{
Yonty Friesem \\ Columbia College Chicago
}

\begin{abstract}
This special issue on media literacy and disability provides a variety of examples and case studies to showcase the importance of addressing issues of disability in the media literacy community. The literature on the intersection of media literacy and disability is slender but suggests four distinct uses of media for students with disabilities. However, none include applying a critical lens to the use of media for students with disabilities. By connecting the practice of critical media literacy with disability theory, this paper offers a theoretical and practical framework for media literacy educators, extending NAMLE's principles of media literacy education to the needs of this important group of learners.
\end{abstract}

Keywords: media literacy, disability, special education, media analysis, media production, critical pedagogy, NAMLE Core Principles

In the age of personalized learning, we see growing attention around the implementation of assistive technology that promotes access for students with disabilities (National Center for Learning Disabilities, 2015). However, these students may not have an opportunity to analyze, create, or reflect upon media messages. Case studies where the National Association for Media Literacy Education (NAMLE) Core Principles (2007) rarely mention adaptations suitable for students with disabilities. By understanding why and how media literacy education may benefit students with disability and special educators, we can address the gap in the literature and develop innovative instructional practices to support learner needs. Combining educational theories (Freire, 1970; Rose \& 
Meyer, 2002) with media literacy education (Buckingham, 2003; Hobbs, 2010; Jenkins, Clinton, Purushotma, Robison, \& Weigel, 2006; McLuhan, 1994[1964]) we can make the case for why and how we can use media literacy education to benefit all students, especially students with disabilities.

This introduction to JMLE special issue on media literacy and disability will review the current state of media literacy education and disability; provide an overview of the articles in this special issue; and suggest a theoretical framework to connect NAMLE core principles with in- and out-of-school practices of media literacy for students with disabilities.

\section{Disability Theory}

People with disabilities are everywhere. In 2011, the World Health Organization conducted surveys in 59 countries across the globe to find that the percentage of people (18 years and older) with disabilities ranged from $11.8 \%$ of the population in higher-income countries to $18.0 \%$ in lower-income countries. Since the passing of the Americans with Disabilities Act (ADA)the number of people with disabilities in the United States has decreased in the last 25 years, , but the U.S. Centers for Disease Control and Prevention (Courtney-Long et al., 2015) still found that, "overall, $22.2 \%$ of U.S. adults (53,316,677 persons) reported any disability. Disability in mobility was the most frequently reported type $(13.0 \%)$, followed by disability in cognition (10.6\%), independent living $(6.5 \%)$, vision $(4.6 \%)$, and self-care (3.6\%)" (p. 779$)$. The report also stated that gender, race, ethnicity, socioeconomic status, and level of education have an effect on the percentage of people with disabilities.

According to the U.S. Census Bureau (2015), there are an estimated 2.88 million (5.4\%) children between the ages of 5-17 with some type of disability. However, according to the National Center for Educational Statistics (NCES) (2016), under the Individuals with Disabilities Education Act (IDEA), formerly known as the Education for All Handicapped Children Act (EAHCA), there are 6.5 million children and youth between the age of 3-21 - or about 13 percent of all public school students - who receive services for their special needs. The main difference between the U.S. Census Bureau report and the NCES is that "among students receiving special education services, 35 percent had specific learning disabilities" (para. 1).

Disability theory applies the social construction of disability to advocate for changes in the environment, as no two disabled people are alike (Siebers, 2008). People with disabilities do not perceive themselves as part of one group since each individual has his/her own special needs, similar to other minority and marginalized groups that include diverse people with particular needs (Solvang, 2000). This is why disability theory calls for a democratic society to be inclusive in order to accommodate all identities and needs. When looking at the practices of special education from the lens of disability theory (Ballard, 2004), we can see the use of separation and exclusion instead of meeting the needs and aspirations of all students.

By looking at inclusive practices and disability instead of using the term special education, we wish to start a productive discourse of how media literacy 
education can promote its core principles to all students. Watson (2012) reviewed the development of disability theory in the last decade and suggested examining the disablement, oppression and exclusion that students with disabilities face. More recently, disability theory examines the identity of the disabled student and his/her psycho-emotional well-being rather than just the access and physical barriers. Therefore, media literacy education can address disability as it is built upon Freire's (2000[1970]) critical pedagogy of liberation through literacy practices.

\section{Media Literacy \& Disability}

Similar to Freire's process of teaching literacy skills to liberate students from oppression, media literacy education aims to enhance students' competencies in access, analysis, creation, reflection, and action (Hobbs, 2010). Nevertheless, there are only few publications about the work of media literacy educators with students who have disabilities. In 1975, the Education for All Handicapped Children Act (EAHCA), which was later renamed the Individuals with Disabilities Education Act (IDEA) reflected increasing concern about equal access to education. Since then, concerns continue regarding the digital divide, accessibility and assistive technology but there has been less focus on media literacy education practices. In the following section, I will review several programs and publications that addressed issues of disability in regard to media literacy.

When teaching media literacy, usually educators can choose to focus on analysis, production, or both. Several researchers have examined the effects of a media literacy curriculum as a form of social scientific intervention. Jeong, Cho, and Hwang (2012) analyzed the effects of 51 media literacy interventions and found that no matter the context, the interventions were generally effective $(d=$ .37) as long as the content was concise. The meta-analysis of these media literacy interventions suggested that the interventions affected many outcomes, leading to increases in knowledge, perceptions of realism, self-efficacy and behaviors, demonstrating the value of media literacy to have a range of positive impacts.

By applying media literacy analysis, students can learn alternative ways to analyze, reflect, and communicate their interpretations of media representations. Back in 1990, Sprafkin, Watkins, and Gadow conducted an experiment to assess the effects of a television-viewing curriculum on first to sixth students with learning disabilities, emotional and behavioral disorders. They found that, after the intervention, students significantly enhanced their television knowledge and identification of aggressive behavior, but less significantly changed their attitudes and viewing habits. Similarly, Sperry (2006) described how American students whose second or third language is English used media literacy analysis to express their views since traditional print decoding was challenging for them. Hobbs, He, \& RobbGrieco (2014) showed how new immigrant teenagers in Philadelphia, with low levels of spoken and written language competence, could engage in meaningful critical analysis of print advertising with appropriate levels of scaffolding and support from their English language arts teacher. 
A number of case studies show the benefits of media production for students with special needs. Students who compose their own messages not only utilize creative ways to express themselves and showcase their interpretation, but also enhance social and emotional skills (Friesem, 2017). Harts (1997) examined how black male students in a special education class benefited from a media literacy and video production curriculum. She found that the students' technical skills and motivation grew while their critical viewing competencies did not. Nevertheless, the practice and learning allowed the students to look for jobs that required the video production skills they had acquired. Pandya, Hansuvadha, and Pagdilao (2016) observed one eight-year old student with autism who enhanced her social interactions and language skills by collaborating on a video production describing her family origins as part of her Individualized Education Plan (IEP). Wadley and Schutt (2013) reported on a successful use of computer lab space for students with Asperger, creating their own media content. Though this improved their social and emotional learning as well as their wellbeing, the activity was focused on making media messages and interaction with others without any analysis or reflection.

While both media literacy practices of analysis and production can promote various skills, the issue of access is still the major barrier for students with disabilities. Dobransky and Hargittai (2006) called for a policy to encourage access to assistive technology for people with disabilities who want to use online communication. More than ten years later, many assistive technologies are available to support mobile media and online engagement (Schaffhauser, 2016). It is also important to note that as the use of Internet and digital devices increases consistently, new concerns about addiction and mental health issues is also rising (Scott, Valley, \& Simecka, 2016). With all the challenges of digital technology, it is time for the media literacy community to address issues of disability and offer evidence-based research and practice to advance media literacy education for all.

\section{Introduction to Special Issue}

In this special issue, we gathered practitioners and researchers who look at various aspects of media literacy and disability. Each article addresses a different aspect from a particular context and age group. Four types of articles are included in this special issue: theory, research, voices from the field, and a review of resources. This special issue explores our current understanding of best practices of media literacy with students who have disabilities, with an emphasis on the current state of media literacy in grades K-16. All articles raise challenges and suggest ways to implement a more inclusive practice of media literacy education. At the end of each article, a section entitled, "Implications" encourages readers to take action by implementing media literacy as an inclusive practice.

Theory. Elizabeth M. Dalton connects the Universal Design for Learning (UDL) framework (Rose \& Meyer, 2002) with digital and media literacy competencies (Hobbs, 2010) as she provides various online platforms to practice it with K-12 students. The framework is built upon the research of cognitive and neuroscience that show how people have various ways to engage in activities, as well as to perceive, process, and express knowledge. The three principles provide 
multiples means of engagement, representation, and expression and can be connected to the five competencies of digital and media literacy (access, analyze, create, reflect, and act). Dalton provides connections to the NAMLE (2007) core principles and makes suggestions for best practices.

April Marie Leach shares her work as a literacy and instructional coach applying the UDL framework and the digital and media literacy competencies with her high school students who have learning disabilities. In alignment with the Common Core State Standards, she describes working on a multimodal media production as part of an intensive reading class. Through one-on-one interviews, Leach demonstrates the power of multimodal media production as an inclusive for students with learning disabilities. She offers her experience and results for media educators to use the UDL framework with the AACRA model (Hobbs, 2010).

Donnell Probst connects five core competencies of social and emotional learning (CASEL, 2017) with NAMLE's (2007) Core Principles. She proposes the use of social media literacy as a framework to create goals for an individualized education plan (IEP) for students with emotional and behavioral disorders. The use of media literacy key questions (Rogow \& Scheibe, 2007) allowed students on the Autism spectrum to analyze visuals from social media to enhance their media literacy skills and improve their social and emotional learning skills (self-awareness, self-management, social awareness, relationship skills, and responsible decision making). Probst provides examples showing how the framework can be used to build IEP goals for students with emotional and behavioral disorders using social media literacy practices.

Research. Elia Powers and Beth Haller examined how 41 journalism and mass communication textbooks used in undergraduate courses address speech disability as an issue of media diversity and access. Textbooks can be perceived as consensus documents and shape the attitudes of undergraduate students toward their future career. It is important that textbooks reflect the growing research on anxiety from public speaking along with the increasing number of people with speech disabilities who are able to work as journalists or broadcasters. Only seven out of the 41 textbooks mentioned speech disabilities. All but one referred to speech disabilities such as stuttering negatively as a barrier and handicap. In their recommendation, Powers and Haller provide suggestions for how textbook authors can frame this issue in a way that increases the likelihood that students with disabilities will view media careers as accessible to them.

Jayne C. Lammers and Nicholas P. Palumbo applied a practitioneroriented version of a "usability inspection" to analyze the accessibility of FanFiction.net. They evaluated the website's content accessibility when trying to perform typical fanfiction tasks using a Screen Reader Technology (SRT). They examined how the use of VoiceOver as a screen reader assistive technology would work for FanFiction.net users. On this popular website, users can share their appreciation for a range of media texts via writing, reading and reviewing. Lammers and Palumbo's research can help media educators to assess online platforms as they apply a new literacies approach (Coiro, Knobel, Lankshear, \& Leu, 2008) and offer their students more accessibility. 
Voices from the Field. Jaclyn K. Siegel describes her work with her high school students who have learning disabilities as they analyzed the presidential election process and campaign messages. Siegel describes in detail how in 2012 and 2016 she taught her students to deconstruct the representation of the presidential nominees in the media. In addition, as part of civic education, one class practiced writing letters to their national and local representatives while another planned presidential campaigns, including the creation of social media. Siegel observed the growth in her students' critical thinking and civic participation. In the appendixes, Siegel offers her teaching materials for media educators to use in their own context.

Karen Festa showcases her work as a special educator in the fourth grade with her co-teacher. Together with their students, they produced book trailers encouraging first graders to read a book written by a local author. Festa explains how it was beneficial for all students - and especially for her students with cognitive learning disabilities - to be part of an analysis and production activity. She describes her journey to apply media literacy practices and how it evolved into her becoming a YouTuber and leading chats on Twitter about educational technology for students with disabilities. Festa offers resources for other special educators and suggestions for implementation in elementary classrooms.

Jayne Cubbage shares her experience teaching media production in higher education while physical barriers are still an issue for students with disabilities. Although ADA and IDEA call for accessible facilities, the location of the class can be crucial in determining who can participate and who cannot. Following NAMLE's (2007) third core principle to 'teach all learners', Cubbage discusses her own experience as well as those of her colleagues who have faced similar challenges in a production classroom. She offers steps to ensure physical accessibility is not a structural barrier for students living with a disability who may also want to learn media production.

Review of Resources. Giuliana Cucinelli provides an overview of three DIY media platforms that she and her colleague created at the Community and Differential Mobilities Research Cluster of the Milieux Institute for Arts, Culture and Technology at Concordia University. The platforms and projects hold a responsibility to offer more access for people with disabilities. Cucinelli reviews a podcast (Adaptive), a mobile app (Montreal*in/accessible), and a DIY maker culture project (Accessible Arcade Tables). She explains how the three projects were helpful for her students as well as for the community in Montreal to raise awareness and provide better access to people with disabilities.

The nine articles in the special issue demonstrate how media literacy practices and NAMLE (2007) core principles can be inclusive as they enhance K16 students' ability to access, analyze, create, reflect, and act. Though the practice and research on media literacy and disability is still in its infancy, each article provides a starting point for further work in the area. Going back to the purpose of critical pedagogy and its strong connections to media literacy, we should look at the reason for applying critical media literacy practices (Kellner \& Share, 2007) as an inclusive practice. In the next section, I would like to offer a framework for applying NAMLE core principles to advance inclusion as a liberating practice. 
Why Should Media Literacy be Inclusive?

Media literacy education advances students' competencies such as critical thinking (Hobbs \& Frost, 2003; Pinkleton, Austin, Chen, \& Cohen, 2012), production skills (Fisherkeller, 2011), engagement in the classroom (Burn \& Durran, 2007; Dezuanni \& Gattenhof, 2015), exploration of own identity and voice (Buckingham, 2008), and civic engagement (Hobbs, Donnelly, Friesem, \& Moen, 2013). For educators, media literacy education provides, in addition to enhancing students' media literacy skills, the ability to perform formative and summative assessment (Friesem, Jennings, \& Prest, 2017; Soep, 2006). When combining analysis practices with production, students' critical analysis skills grow (Banerjee \& Greene, 2006; Ranieri\& Fabbro, 2016). And yet, there are only few reports on applying media literacy practices that include people with disabilities.

When we explore the use of digital media in special education, four different purposes for the use of technology is evidence as it assists, educates, makes, or promotes health. With each purpose, there is a specific desired outcome and practice. As media educators, we are interested in the use of media for engaging students using a critical lens. This is an interesting category to examine the use of media for students with disabilities since none of these types uses media literacy practices (Norman \& Skinner, 2006).

Table 1

The Use of Digital Media in Special Education

\begin{tabular}{llll}
\hline Type & Outcome & Practice & Critical Lens \\
\hline Assistive & Access & Integrating & Transparent \\
Educational & Inform & Receiving & Overlooked \\
Maker & Expression & Producing & Unquestioned \\
eHealth & Treatment & Intervention/Rehab & Not encouraged \\
\hline
\end{tabular}

The first type of use of digital media in special education, the use of assistive technologies, has the purpose of providing students with disabilities to have equal access to media content and learning experiences. Therefore, various media applications are designed to overcome the barriers of physical, mental, cognitive, social, and emotional disabilities by providing as equal access as possible for student with disabilities. The main goal of assistive technology is to "increase, maintain, or improve the functional capabilities of a child with a disabilities" (IDEA, 2015, p. 6, Sec.602). Assistive technology can come in many forms: a piece of software, an application, a website, or a mechanical tool. It can help with reading, writing, speaking, listening, calculating, problem-solving, or communication, and it can augment vision or sound or highlight parts of other media (Dell, Newton, \& Petroff, 2017). Depending on the learning activity, the use of the media as assistive technology might be active or passive. The use of the media is meant to provide access for learning, so the student might be actively using the media, but it is a more transparent use. By transparent, I mean it is 
becoming a part of assisting the students' senses to perceive the information and there is not a great amount of metacognitive reflection on the use itself. In other words, assistive technology is a tool to enhance learning, but rarely its designers provide the users a critical lens (Mankoff, Hayes, \& Kasnitz, 2010).

The second type of use of digital media in special education, the concept of educational technology is a broad term to define media that "involves the disciplined application of knowledge for the purpose of improving learning, instruction and/ or performance" (Spector, 2016, p. 10). Educational books, videos, pictures, artifacts, podcasts, applications, games, and online course are some of the various types of media that can be used in the classroom to inform students. While the use of mobile media promotes greater engagement, it usually lacks the reflection and critical inquiry that is necessary to deconstruct its representations and goals to enhance learning (Agostinho, Ginns, Tindall-Ford, Mavilidi, \& Paas, 2016). Like 'typical' students, students with disabilities receive information without asking key critical questions. As receivers of knowledge, even if it is done actively on a device, most of the students do not apply a metacognitive reflection of the purpose and design of the media (Kearsley, 1998). Educators who are not familiar with NAMLE (2007) core principles and the practice of critical media literacy overlook the purpose, design, power relations, and economics behind the media messages of educational technologies.

The third type of use of digital media in special education, the maker movement, "refers to the growing number of people who are engaged in the creative production of artifacts in their daily lives and who find physical and digital forums to share their processes and products with others" (Halverson \& Sheridan, 2014, p. 496). The process of producing a product can be on a variety of platforms such as 3D printer, programming, hardware, applications, robotics, videography, and analog devices. As students with disabilities participate in a production activity, they are expressing themselves using technology. Similarly to assistive and educational technology, the use of media for production is usually aesthetically and technically-focused. When a maker class focuses more on the product and not the process, it may undermine the ability to critically look at the purpose of expressing through production (Blikstein \& Worsley, 2016). While the students have ownership of their products, they may not question themselves as to the effects of their creation and to the sociocultural influences on their production process.

The fourth type of use of digital media in special education, eHealth is a term that includes the use of technology to "for supporting healthcare and promoting a sense of well-being" (Nijland, 2011, p. 13). The technology can be used as a tool for intervention or a rehabilitation. In both cases, the media is part of a treatment to improve the health of the student with disabilities. With the increase of Internet use with mobile devices, there is a growing number of eHealth integration. Nevertheless, these practices have several disadvantages according to Konrath (2015): many scholars who examined these areas focus on basic outcomes of eHealth; the technology quickly becomes obsolete; there is less privacy and confidentiality in the age of social media and mobile photography; and issues arise when people replace face-to-face treatment with online 
interactions. In relation to media literacy, Konrath mentioned that not all users have access to smartphones nor the literacy skills to use them wisely. In addition, the traditional power relationship between the physician, interventionist, or therapist with their patients is challenged with the use of technology. With the use of technology, there is a call to design an alignment between the concerns of the patients and the caregivers in order to address the issue of power relations with eHealth (Andersen, Bansler, Kensing, Moll, \& Nielsen, 2014). But critically analyzing the practice of the physician, interventionist, or therapist is not a usual practice.

Going back to disability theory, these four practices raise questions about the benefits for students with disabilities. The four practices enhance students' skills, but do not seem to be transformative and liberating. When Denski (1991) reflected on media literacy practices in higher education, he advocated for a pedagogy of hope: "The continued development of a critical theory of media education offers the potential of a pedagogy of empowerment, resistance, invention, and hope. The building of bridges between critical pedagogy and media studies represents a first step in this project" (p.14). One of the examples where youth media can be used as a practice of liberation and critical pedagogy can be found in Steve Goodman's book Teaching Youth Media: A Critical Guide to Literacy, Video Production, and Social Change (2003). Goodman described how a yearlong workshop with high school students from Brooklyn and Harlem allowed them to use the power of digital media to inquire, produce, distribute, advocate, and make a change in their own community. When looking at people with disabilities, we should apply the same successful practices.

When an educator uses digital media for either assistive technology, information, expression, or intervention, in an inclusive class, it has a transformative effect. This form of activism engages both 'typical' and 'special' students in an educational activity that helps break down the barriers of exclusion due to disabilities. Siebers (2008) explained the importance of inclusion in having people with disabilities be the biggest minority in the US. Some disability can be seen easily while others are hidden or undiagnosed. As media educators, we should use the available instructional practices, curriculum, and technology to be inclusive and reach all students and send a message of social responsibility and liberation.

If we want to have media literacy education for all students, there should be an inclusive framework that allows media educators to enhance all their students' media literacy skills. Kellner and Share 's (2007) multiperspectival approach addressed issues of gender, race, class, sexuality, and power, but excluded disabilities. For Kellner and Share, critical media literacy "deepens the potential of literacy education to critically analyze relationships between media and audiences, information, and power" (p. 60). Table 2 suggests various critical media literacy practices in relation to disabilities for an inclusive class according to the NAMLE (2007) core principles. 
Table 2

Inclusive Framework of Media Literacy Education

NAMLE (2007) Core Principles Practice in regards to Disabilities

Foundation of media literacy education

1 Requires active inquiry \& critical thinking Adding critical questions about the representations and power relations of disabilities, and the various types of disabilities.

2 Expends literacy to all media

Exploring the ways different media platforms provide access to different abilities and disabilities.

\section{Outcomes of media literacy education}

3 Skill-based for all learners

Allowing the practice of media literacy to enhance the skills of all learners using UDL.

4 Informed, reflective and civically engaged

Reflecting on one's own abilities and disability in regards to others.

Values, culture, and ecosystem

5 Media are cultural agents of socialization

As part of representing diverse voices, using texts about various types of disabilities and the responsibility of representing the diversity of disability.

6 People construct their own meaning Examining one's own bias toward disabilities while understanding and appreciating other perspective on disability.

Note: Adapted from the Core Principles of Media Literacy Education in the United States (NAMLE, 2007)

In this special issue, the nine articles describe how to implement these principles in regard to disabilities. The first principal proposes that we inquire, be critical, and add critical questions about the representations and power relations of disabilities, along with the various types of disabilities. Powers and Haller accomplish this when they critically analyzed 41 journalism and mass communication textbooks, as did Lammers and Palumbo when they critically examined FanFiction.net. The critical lens of inquiry can be adopted from both articles to be used in the classroom.

The second principle looks at the expansion of media literacy. Exploring the ways different media platforms provide access to different abilities and disabilities can promote better literacy skills. Cucinelli describes three distinctive media projects that allowed her students to build platforms to expand the use of 
media for people with disabilities. By producing and analyzing the various platforms and their use, students can see how each medium expend the access for different people.

The third principle is the most inclusive of all, calling for building and reinforcing skills for all learners. The first two articles suggest applying the Universal Design for Learning (UDL) as an evidence-based educational practice to address all learners. Dalton connects UDL with digital and media literacy competencies (access, analyze, create, reflect, act) to show how can media educators apply UDL. Leach provides her own experience using UDL with high school students who produce media as part of her work as a literacy and instructional coach.

The fourth principle states that media literacy education develops informed, reflective and engaged citizens essential for a democratic society. Reflecting on one's own abilities and disability in regards to others, we can learn to be more informed and responsible citizens. In her article, Siegel shares how her curriculum in social science applied media literacy practices to learn and engage in the 2012 and 2016 presidential election. As part of her pedagogy, she addresses issues of learning disabilities and showcases how it affected the students.

The fifth principle talks about recognizing that media are a part of culture and function as agents of socialization. As part of deconstructing cultural texts, demystifying their values and roles as agents of socialization, educators should provide texts that represent diverse voices of disabilities as well as the responsibility of representing the various types of disability. Probst suggests an IEP of social media literacy, to practice critical analysis of visuals by students with emotional and behavioral disorders. Cubbage describes how the institutional bureaucracy created barriers for her media production undergraduate student who has physical disabilities. In both articles, the authors reflect on the way media literacy education can not only reflect on the culture, but become active agent of change.

The sixth principle affirms that people use their individual skills, beliefs and experiences to construct their own meanings from media messages. Examining one's own bias toward disabilities while understanding and appreciating other perspective on disability can promote a better understanding of diversity and appreciation of own values. In her article, Festa describes how her fourth-grade students created book trailers in groups to represents various perspectives. As the students in her inclusive classroom underwent the process of production, all students, and especially the students with various disabilities, benefitted from the process and the final showcase. The screening of the trailer in front of the local author and the first grade gave an opportunity for her students to reflect on their own values.

\section{Call for Action}

Teaching media literacy in an inclusive classroom is a form of activism. "It requires a democratic pedagogy, which involves teachers sharing power with students as they join together in the process of unveiling myths, challenging hegemony, and searching for methods of producing their own alternative media" 
(Kellner \& Share, 2007, p. 64). Only when activism will become a fifth type of practice alongside the other four (assistive, educational, makers, eHealth) will people with disabilities become fully included in media literacy education. Until then, it is our responsibility as practitioners, scholars, and advocates to actively promote inclusive practices that advance the media literacy skills of all. Building upon the historical roots of media literacy education (Freire, 2000[1970]; McLuhan, 1994[1964]), we advocate for people to understand and decode media messages, compose effective messages, reflect upon their media consumption, be socially responsible, and be social change agents in a democratic society. For people with disabilities these media literacy competencies are as equally important if not even more significant beyond accessibility.

\section{References}

Individuals with Disabilities Education Improvement Act Amendments of 2015 [IDEA], 601 (2015). Retrieved from https://legcounsel.house.gov/Comps/Individuals\%20With\%20Disabiliti es $\% 20$ Education $\% 20$ Act.pdf

Agostinho, S., Ginns, P., Tindall-Ford, S., Mavilidi, M., \& Paas, F. (2016). Touch the screen': Linking touch-based educational technology with learning - A synthesis of current research. In L. Lin, \& R. R. Atkinson (Eds.), Educational technologies: Challenges, applications and learning outcomes (pp. 33-57). New York, NY: Nova Publishing.

Andersen, T., Bansler, J., Kensing, F., Moll, J., \& Nielsen, K. D. (2014). Alignment of concerns: A design rationale for patient participation in ehealth. Paper presented at the the 47th Hawaii International Conference on System Sciences (HICSS), Waikoloa, HI. 2587-2596. https://doi:10.1109/HICSS.2014.327

Ballard, K. (2004). Children and disability: Special or included. Waikato Journal of Education, 10, 315-326. https://doi:10.15663/wje.v10i1.349

Banerjee, S. C., \& Greene, K. (2006). Analysis versus production: Adolescent cognitive and attitudinal responses to antismoking interventions. Journal of Communication, 56(4), 773-794. https://doi:10.1111/j.14602466.2006.00319.x

Blikstein, P., \& Worsley, M. (2016). Children are not hackers: Building a culture of powerful ideas, deep learning, and equity in the makers movement. In K. A. Peppler, E. R. Halverson \& Y. B. Kafai (Eds.), Makeology: Makerspaces as learning environments (Volume 1 ed., pp. 64 - 79). New York, NY: Routledge.

Buckingham, D. (2003). Media education: Literacy, learning and contemporary culture. Cambridge, UK: Polity.

Buckingham, D. (Ed.). (2008). Youth, identity, and digital media. Cambridge, MA: The MIT Press and The John D. and Catherine T. MacArthur Foundation Series on Digital Media and Learning. Retrieved from http://mitpress.mit.edu/sites/default/files/titles/free download/9780262 524834 Youth Identity and Digital_Media.pdf 
Burn, A., \& Durran, J. (2007). Media literacy in schools: Practice, production and progression. London, UK: Paul Chapman.

CASEL. (2017). Social and emotional learning core competencies. Retrieved from http://www.casel.org/social-and-emotional-learning/core-competencies

Coiro, J., Knobel, M., Lankshear, C., \& Leu, D. J. (Eds.). (2008). Handbook of research on new literacies. New York, NY: Taylor \& Francis.

Courtney-Long, E. A., Carroll, D. D., Zhang, Q. C., Stevens, A. C., GriffinBlake, S., Armour, B. S., \& Campbell, V. A. (2015). Prevalence of disability and disability type among adults — United States, 2013. Morbidity and Mortality Weekly Report, 64(29), 777-783. Retrieved from https://www.cdc.gov/mmwr/pdf/wk/mm6429.pdf

Dell, A. G., Newton, D. A., \& Petroff, J. G. (2017). Assistive technology in the classroom: Enhancing the school experiences of students with disabilities(3rd ed.). Boston, MA: Pearson.

Denski, S. W. (1991). Critical pedagogy and media production: The theory and practice of the video documentary. Journal of Film and Video, 43(3, Pedagogies of Production), 3-17. Retrieved from http://www.jstor.org/stable/20687938

Dezuanni, M., \& Gattenhof, S. (2015). Digital media literacies in the early years. In M. Dezuanni, K. Dooley, S. Gattenhof \& L. Knight (Eds.), iPads in the early years: Developing literacy and creativity (pp. 66-85). Oxon, UK: Routledge.

Dobransky, K., \& Hargittai, E.,. (2006). The disability divide in Internet access and use. Information, Communication \& Society, 9(3), 313-334. https://doi:10.1080/13691180600751298

Education for all handicapped children act (EAHCA), P.L. 94-142U.S.C. 1400 (1975).

Fisherkeller, J. (Ed.). (2011). International perspectives on youth media: Cultures of production and education. New York, NY: Peter Lang.

Freire, P. (2000[1970]). Pedagogy of the oppressed (M. Bergman Ramos Trans.). (30th Anniversary edition ed.). New York, NY: Bloomsbury Academic.

Friesem, Y. (2017). The media production hive: Using media education for differentiated instruction. Media Education: Studies, Research, Best Practice, 8(1), 123-140. https://doi:10.14605/MED811708

Friesem, Y., Jennings, B., \& Prest, C. (2017). Let it go: A journey toward elementary student-driven media production aligned with the CCSS. In M. T. Grassetti, \& S. Brookby (Eds.), Advancing next-generation elementary teacher education through digital tools and applications (pp. 245-261). Hershey, PA: IGI Global. https://doi:10.4018/978-1-5225-0965-3.ch013

Goodman, S. (2003). Teaching youth media: A critical guide to literacy, video production \& social change. New York, NY: Teachers College Press.

Halverson, E. R., \& Sheridan, K. (2014). The maker movement in education. Harvard Educational Review, 84(4), 495-504.

Harts, M. L. (1997). Media literacy and video technology: Educational and motivational tools to empower African-American males in special education. Ph.D. thesis, Teachers College, Columbia University. 
Hobbs, R. (2010). Digital and media literacy: A plan of action. (White Paper). Washington, D.C.: The Aspen Institute.

Hobbs, R., He, H. \& RobbGrieco, M. (2014). Seeing, believing and learning to be skeptical: Supporting language learning through advertising analysis activities. TESOL Journal. https://DOI:10.1002/tesj.153

Hobbs, R., \& Frost, R. (2003). Measuring the acquisition of media-literacy skills. Reading Research Quarterly, 38(3), 330-355. https://doi:10.1598/RRQ.38.3.2

Hobbs, R., Donnelly, K., Friesem, J., \& Moen, M. (2013). Learning to engage: How positive attitudes about the news, media literacy, and video production contribute to adolescent civic engagement. Educational Media International, 50(4), 231-246. https://doi:10.1080/09523987.2013.862364

Individuals with Disabilities Education Act (IDEA), P.1. 105-17U.S.C. 1400 (2004).

Jenkins, H., Clinton, K., Purushotma, R., Robison, A. J., \& Weigel, M. (2006). Confronting the challenges of participatory culture: Media education for the 21st century. (). Chicago, IL: The John D.and Catherine T. MacArthur Foundation.

Jeong, S., Cho, H., \& Hwang, Y. (2012). Media literacy interventions: A metaanalytic review. Journal of Communication, 62(3), 454-472. https://doi:10.1111/j.1460-2466.2012.01643.x

Kearsley, G. (1998). Educational technology: A critique. Educational Technology, 38(2), 47-51.

Konrath, S. (2015). Positive technology: Using mobile phones for psychosocial interventions. In Y. Zheng (Ed.), Encyclopedia of mobile phone behavior (pp. 871-897). Hershey, PA: IGI Global. https://doi:10.4018/978-14666-8239-9.ch072

Mankoff, J., Hayes, G. R., \& Kasnitz, D. (2010). Disability studies as a source of critical inquiry for the field of assistive technology. Paper presented at the Proceedings of the 12th International ACM SIGACCESS Conference on Computers and Accessibility, Orlando, Florida, USA. 3-10. https://doi:10.1145/1878803.1878807

McLuhan, M. (1994[1964]). Understanding media: The extensions of man. Cambridge, MA: MIT Press.

National Association for Media Literacy Education. (NAMLE). (2007). Core principles of media literacy education in the United States. Retrieved from http://namle.net/publications/core-principles/

National Center for Education Statistics (May 2016). Children and youth with disabilities. The Condition of Education. Washington, DC: Department of Education.

National Center for Learning Disabilities. (2015). Personalized learning: Policy $\&$ practice recommendations for meeting the needs of students with disabilities. New York, NY: National Center for Learning Disabilities.

Nijland, N. (2011). Grounding eHealth: Towards a holistic framework for sustainable eHealth technologies. Thesis, University of Twente. Retrieved from http://doc.utwente.nl/75576/1/thesis_N_Nijland.pdf 
Norman, D. C., \& Skinner, A. H. (2006). eHealth literacy: Essential skills for consumer health in a networked world. Journal of Medical Internet Research, 8(2), e9. https://doi:10.2196/jmir.8.2.e9

Pinkleton, B. E., Austin, E. W., Chen, Y., \& Cohen, M. (2012). The role of media literacy in shaping adolescents' understanding of and responses to sexual portrayals in mass media. Journal of Health Communication, 17(4), 460-476. https://doi:10.1080/10810730.2011.635770

Ranieri, M., \& Fabbro, F. (2016). Questioning discrimination through critical media literacy. Findings from seven European countries. European Educational Research Journal, 15(4), 462 - 479. https://doi:10.1177/1474904116629685

Rogow, F., \& Scheibe, C. (2007). Key questions to ask when analyzing media messages. Cherry Hill, NJ: National Association for Media Literacy Education. Retrieved from https://drive.google.com/file/d/0B8j2T8jHrlgCZ2Zta2hvWkF0dG8/vie $\mathrm{W}$

Rose, D. H., \& Meyer, A. (2002). Teaching every student in the digital age: Universal design for learning. Alexandria, VA: Association for Supervision and Curriculum Development (ASCD).

Schaffhauser, D. (2016, November 16). Groups issue guidance on making digital learning accessible to all. THE Journal Retrieved from https://thejournal.com/articles/2016/11/16/groups-issue-guidance-onmaking-digital-learning-accessible-to-all.aspx

Scott, D. A., Valley, B., \& Simecka, B. A. (2016). Mental health concerns in the digital age. International Journal of Mental Health and Addiction 15(3), 604 - 613. https://doi:10.1007/s11469-016-9684-0

Siebers, T. (2008). Disability theory. Ann Arbor, MI: University of Michigan Press. https://doi:10.3998/mpub.309723

Soep, E. (2006). Critique: Assessment and the production of learning. The Teachers College Record, 108(4), 748-777. Retrieved from http://ncm.gu.se/files/38_12368.pdf

Solvang, P. (2000). The emergence of an us and them discourse in disability theory. Scandinavian Journal of Disability Research, 2(1), 3-20. https://doi:10.1080/15017410009510749

Spector, M. J. (2016). Foundations of educational technology: Integrative approaches and interdisciplinary perspectives (2nd ed.). New York, NY: Routledge.

Sperry, C. (2006). Seeking truth in the social studies classroom: Media literacy, critical thinking and teaching about the middle east. Social Education, 70(1), 37-43.

Sprafkin, J., Watkins, L. T., \& Gadow, K. D. (1990). Efficacy of a television literacy curriculum for emotionally disturbed and learning disabled children. Journal of Applied Developmental Psychology, 11(2), 225-244. https://doi:10.1016/0193-3973(90)90007-7

US Census Bureau. (2015). Disability characteristics. (No. S1810). Washington, DC: US Census Bureau. 
Wadley, G., \& Schutt, S. (2013). Hanging out at the computer lab: How an innovative Australian program is helping young 'aspies'. Paper presented at the Proceedings of the 25th Australian Computer-Human Interaction Conference: Augmentation, Application, Innovation, Collaboration, Adelaide, Australia. 535-538. https://doi:10.1145/2541016.2541078

Watson, N. (2012). Theorising the lives of disabled children: How can disability theory help? Children \& Society, 26(3), 192-202. https://doi:10.1111/j.10990860.2012.00432.x

World Health Organization. (2011). World report on disability. (No. NLM classification: HV 1553). Geneva, Switzerland: World Health Organization. 